\title{
Radiotherapy for Colorectal Cancer: Current Standards and Future Perspectives
}

\author{
Matthias F. Häfner ${ }^{a, b}$ Jürgen Debus ${ }^{a, b}$ \\ ${ }^{a}$ Department of Radiation Oncology, Heidelberg University Hospital, Heidelberg, Germany; \\ ${ }^{b}$ Heidelberg Institute of Radiation Oncology (HIRO), Heidelberg, Germany
}

\section{Keywords}

Radiotherapy · Colorectal cancer · Chemoradiotherapy · Rectal cancer

\section{Summary}

Background: Multimodal treatment approaches are indispensable for patients with advanced-stage colorectal cancer. Radiotherapy has been established as essential part of perioperative concepts and was introduced as an option to face challenges such as local relapse or oligometastases. Methods: A literature review was performed to summarize evidence and current standards of radiotherapeutic concepts in the treatment of colorectal cancer. Results: For stage II/III rectal cancer, neoadjuvant radiotherapy is superior to adjuvant treatment. Two preoperative regimens have been established and are commonly used with different objectives: short-course radiotherapy (SC-RT) and long-course chemoradiotherapy (LC-CRT). Both reduce the risk of local relapse. Additionally, LC-CRT aims at downsizing the tumor to potentially reduce radicalness of surgery. There is increasing evidence that not all stage II/III rectal cancer patients need neoadjuvant irradiation but also that in some cases surgery might be omitted. Stereotactic body radiotherapy (SBRT) of the liver shows high rates of local control in oligometastatic patients. Intraoperative and particle radiotherapy extend the spectrum of treatment options for locally recurrent patients. Conclusion: Radiotherapeutic concepts are crucial for the primary management of locally advanced colorectal cancer and can essentially contribute to treatment approaches in locally recurrent, oligometastatic or palliative patients.

(c) 2016 S. Karger GmbH, Freiburg

\section{Introduction}

Colorectal cancer (CRC) is one of the most commonly diagnosed malignant neoplasms worldwide, with an estimated 1.4 million occurrences and almost 700,000 deaths in 2012. Regions of high incidence are Northern America, Europe, and Australia/New Zealand [1]. In contrast to a mainly rising incidence rate over the last 20-30 years, specific mortality rates of CRC have decreased in a large number of countries, most likely due to screening examinations, prevention programs, and improved treatment options [1]. Advances in multimodal treatment strategies involving all major oncologic disciplines have contributed to a remarkably improved prognosis for affected patients. For rectal cancer in particular, radiotherapy has been established as a mainstay of treatment alongside surgery. In the present article, we review the role of radiotherapy in the management of CRC with a special focus on current treatment standards for locally advanced rectal cancer and provide an outlook on future challenges and approaches.

\section{Neoadjuvant Radiotherapy}

At the end of the 1980s and during the 1990s, evidence was growing that an addition of radiotherapy to exclusively surgical treatment of rectal cancer could improve patients' prognosis. After the first prospective trials initiated in that phase had released their long-term results, a paradigm shift in the management of locally advanced rectal cancer took place towards multimodal treatment strategies.

The Swedish Rectal Cancer Trial was one of the first major studies in which a significant benefit of neoadjuvant irradiation compared to surgery alone [2] was found. By preoperatively applying a short-course radiotherapy (SC-RT) of $5 \times 5 \mathrm{~Gy}$, the overall survival (OS) was significantly improved from 30 to $38 \%(\mathrm{p}=0.008$ ), and the local recurrence rate (LRR) decreased from 26 to $9 \%$ (p < 
0.001). However, as surgical quality was also improved dramatically by the introduction of total mesorectal excision (TME) resulting in significantly lower recurrence rates [3, 4], the Swedish data from the pre-TME era are not applicable to the present. In a Dutch trial, the addition of preoperative SC-RT to TME surgery improved LRR from 11 to $5 \%(\mathrm{p}<0.0001)$ but did not result in a better OS (49 vs. $48 \%$; $\mathrm{p}=0.86$ ) [5]. In the MRC CR07 trial, preoperative SC-RT was tested against selective adjuvant chemoradiation for high-risk patients with a positive circumferential resection margin $(\mathrm{CRM}+)$. TME was not obligatory but equably balanced between both treatment arms. Though selective postoperative treatment did not influence OS after 3 years (76.7 vs. 74.4\%; $\mathrm{p}=0.04$ ), LRR was remarkably higher with $10.6 \%$ compared to preoperative SC-RT with $4.4 \%$ ( $\mathrm{p}<0.0001)$ [6].

Alternatively to SC-RT, the combination of normofractionated irradiation with radiation doses between 45 and 50.4 Gy and simultaneous application of chemotherapy was established as longcourse chemoradiotherapy (LC-CRT). The German CAO/ARO/ AIO-94 trial introduced a 5-fluorouracil(5-FU)-based CRT approach and demonstrated an advantage of preoperative over postoperative application in terms of 10 -year LRR (7.1 vs. $10.1 \%$; $\mathrm{p}=$ 0.048 ) but not in OS $[7,8]$. Omitting the chemotherapeutic component in preoperative long-course treatment does not affect OS negatively but results in a worse LRR as Gérard et al. [9] were able to demonstrate. Alternatively to 5-FU-based approaches, capecitabine can be used in preoperative LC-CRT [10].

With two available neoadjuvant concepts, SC-RT and LC-CRT, the question arose whether one of them is superior to the other and should thus be used preferably in daily practice. Several works addressed this topic, and Bujko et al. [11] presented first results in a randomized controlled trial. After a median follow-up of 4 years, no differences in OS or LRR were observed. The Trans-Tasman Radiation Oncology Group presented comparable prognostic results in 2012 for both strategies, with a 5-year OS of 74 versus $70 \%$ ( $\mathrm{p}=0.62)$ and a 3 -year LRR of 7.5 versus $4.4 \%(\mathrm{p}=0.24)$ for SC-RT versus LC-CRT [12]. However, both studies were criticized because of a rather small patient number and short follow-up. Further, two Cochrane Database reviews with the same question and quite similar inclusion criteria (stage III or stage II/III) tried to determine the preferable concept, and both found a superiority of LC-CRT compared to radiotherapy alone in terms of LRR $[13,14]$. However, the meta-analyses contained only 5 or 6 studies with very heterogeneous treatment regimens and in part cohorts with pre-TME surgery limiting the informative value.

From a clinical point of view, SC-RT and LC-CRT are not competing but complementary strategies with a separate scope of use and partly different therapeutic goals: concordantly, both strategies aim to reduce the risk of local relapse. But as reflected in the major clinical guidelines [15-17], SC-RT is commonly recommended in early T3 stage without lymph node involvement, whereas LC-CRT is indicated for advanced T3 and T4 tumors with positive clinical circumferential resection margin (cCRM+) and/or positive lymph nodes to additionally downsize the tumor. The downsize effect aims at increasing the probability of $\mathrm{R} 0$ resection and in special cases to preserve the sphincter muscle. Adjuvant chemoradiation should be avoided by thorough diagnostic work-up before treatment onset. Further, the management of proximal rectal cancer, i.e. $12-16 \mathrm{~cm}$ from the anal verge, is debated controversially due to the anatomical setting und the underrepresentation in the mentioned studies. A detailed overview of the relevant, major randomized trials for neoadjuvant SC-RT or LC-CRT is shown in table 1 .

\section{Toxicity}

Besides the undisputed importance of acute toxicity in the evaluation of a treatment modality, late side effects of neoadjuvant radiotherapy in rectal cancer deserve special attention due to the functional sensitivity of concerned structures like the anal sphincter or the urinary tract. Long-term follow-up data from the Dutch trial [18] or Swedish cohorts [19] suggested high rates of fecal and urinary incontinence after SC-RT compared to surgery alone, thus impairing quality of life. However, from today's perspective, old radiation techniques were used in these trials. More recent toxicity data from the British MRC CR07 trial also showed increased fecal incontinence rates associated with SC-RT; however, in most of the affected patients changes were reported on a low-grade level with rather minor impact on the quality of life [20].

Higher rates of acute toxicity are rather observed with LC-CRT than SC-RT, but incidence rates of late side effects do not show significant differences [11-14]. Gender-specific analyses of toxicity showed a significantly higher rate of hematologic and acute organ toxicity for female patients in the cohort of the German CAO/ARO/ AIO-94 trial [21] and an increased rate of dyspareunia and vaginal dryness [22]. However, these data also resulted from outdated treatment application modes. Further, there was a slightly increased rate of sexual dysfunction compared to surgery alone in male patients treated with SC-RT; however, the main reason for sexual dysfunction was surgical morbidity[0] [20]. [20]. A recent pooled analysis of the Dutch trial [5] and the PORTEC trials for RT of endometrial cancer $[23,24]$ did not show an increased rate of secondary malignancies associated with RT [25]. However, there is no comparable analysis for combined CRT. Finally, neoadjuvant RT or CRT do not seem to deteriorate perioperative morbidity $[26,27]$.

\section{Future Perspectives}

Technical progress due to advanced radiation delivery techniques has found its way into the treatment of rectal cancer as well. Especially intensity-modulated radiotherapy (IMRT) has been broadly established in clinical use and has shown potential benefits with decreased toxicity for rectal cancer patients by reducing the radiation dose applied to the organs at risk $[28,29]$. With particle irradiation (e.g. protons) even higher conformity of the therapeutic dose level and lower doses at healthy tissue seem possible, and the first planning studies have shown encouraging results [30]. On the 
Table 1. Key trials for neoadjuvant RT of rectal cancer

\begin{tabular}{|c|c|c|c|c|c|c|c|c|}
\hline Reference & Treatment & $\mathrm{n}$ & TME & FU & OS & LRR & $\mathrm{pCR}$ & Comment \\
\hline Folkesson et al. [2] & i) SC-RT + surg & 908 & no & 156 & 13 years: $38 \%^{\mathrm{a}}$ & 13 years: $9 \%^{\mathrm{a}}$ & n.d. & \\
\hline Swedish Rectal Cancer Trial & ii) surg & & & & 13 years: $30 \%^{\mathrm{a}}$ & 13 years: $26 \%^{\mathrm{a}}$ & n.d. & \\
\hline van Gijn et al. [5] & i) SC-RT + surg & 1,861 & yes & 139 & 10 years: $49 \%$ & 10 years: $5 \%^{\mathrm{a}}$ & n.d. & \\
\hline Dutch Rectal Cancer Trial & ii) surg & & & & 10 years: $48 \%$ & 10 years: $11 \%^{\mathrm{a}}$ & n.d. & \\
\hline Sebag-Montefiore et al. [6] & i) SC-RT + surg & 1,350 & (yes) & 48 & 3 years: $51.5 \%$ & 3 years: $4.4 \%^{\mathrm{a}}$ & n.d. & TME optional \\
\hline MRC CR07 & $\begin{array}{l}\text { ii) surg + LC-CRT } \\
(\mathrm{CRM}+)\end{array}$ & & & & 3 years: $53.4 \%$ & 3 years: $10.6 \%^{\mathrm{a}}$ & n.d. & balanced \\
\hline Gérard et al. [9] & i) LC-CRT + surg & 733 & (yes) & 81 & 5 years: $67.4 \%$ & 5 years: $8.1 \%^{\mathrm{a}}$ & $11.4 \%^{\mathrm{a}}$ & TME recommended \\
\hline FFCD 9203 & ii) LC-RT + surg & & & & 5 years: $67.9 \%$ & 5 years: $16.5 \%^{\mathrm{a}}$ & $3.6 \%^{\mathrm{a}}$ & \\
\hline Sauer et al. [8] & i) LC-CRT + surg & 799 & yes & 134 & 10 years: $59.6 \%$ & 10 years: $7.1 \%^{\mathrm{a}}$ & $8 \%$ & \\
\hline CAO/ARO/AIO-94 & ii) surg + LC-CRT & & & & 10 years: $59.9 \%$ & 10 years: $10.1 \%^{\mathrm{a}}$ & n.a. & \\
\hline \multirow[t]{2}{*}{ Bujko et al. [11] } & i) SC-RT + surg & 312 & yes & 48 & 4 years: $67.2 \%$ & 4 years: $10.6 \%$ & $0.7 \%^{\mathrm{a}}$ & \\
\hline & ii) LC-CRT + surg & & & & 4 years: $66.2 \%$ & 4 years: $15.6 \%$ & $16.1 \%^{\mathrm{a}}$ & \\
\hline Ngan et al. [12] & i) SC-RT + surg & 326 & (no) & 71 & 5 years: $74 \%$ & 3 years: $7.5 \%$ & $1 \%^{\mathrm{a}}$ & TME not routinely \\
\hline TROG 01.04 & ii) LC-CRT + surg & & & & 5 years: $70 \%$ & 3 years: $4.4 \%$ & $15 \%^{\mathrm{a}}$ & (NHMRC GL 1999) \\
\hline
\end{tabular}

aStatistically significant.

$\mathrm{n}=$ Patient number; TME = total mesorectal excision; FU = median follow-up; OS = overall survival; LRR = local relapse rate; $\mathrm{pCR}=$ pathological complete remission; SC-RT = short-course radiotherapy; surg = surgery; LC-CRT = long-course chemoradiotherapy (5-FU- or capecitabine-based); CRM+ = positive circumferential resection margin; n.d. = not done.

one hand, this development is expected to reduce rather high toxicity rates reported in the large, major trials mentioned above. On the other hand, a higher precision of the radiation beam also bears a higher risk of geographical miss of the target volume. Hence, advanced delivery techniques, especially particle RT, need further clinical validation.

Besides these technical aspects of dose delivery, the main future challenge for the management of rectal cancer is the identification of certain risk constellations that allow more differentiated and personalized treatment recommendations, especially for the highly debated heterogeneous group of stage II/III patients. Currently, two major approaches can be observed and are described in the following.

\section{Local De-Escalation}

After neoadjuvant RT has become a general recommendation for all stage II/III rectal cancer patients, the question emerged whether actually every patient of this group needs preoperative treatment, and, if not, how patients who probably will not benefit can be selected [31, 32]. Indeed, the introduction of TME lead to a significant improvement of local tumor control, and the OS advantage of neoadjuvant RT vanished. However, the addition of neoadjuvant RT to TME surgery reduces the risk of local relapse approximately by $50 \%$, e.g. from 11 to $5 \%$ in the Dutch trial [5]. Estimated from that data, the number needed to treat in order to prevent one local relapse is approximately 20 . The basic hypothesis for the identification of patients suitable for an exclusively surgical concept is that patients with negative nodal status, negative cCRM, and safe distance to the anal verge are unlikely to benefit from RT. So far, retrospective data suggest the permissibility of that approach, but at the same time they are too biased in terms of imbalanced collectives, short follow-up, and uncontrolled data to conclusively contribute to the question [26]. Further, very sensitive and specific diagnostic tools are necessary to prospectively select these patients. With an advanced thin slice protocol of magnetic resonance imaging (MRI), the MERCURY study group has developed a strong tool with a high prediction rate of pathological CRM status and a low rate of false-negative findings $[33,34]$. However, the relevance of nodal status remains unclear. Further, there are findings from major studies that conflict with the hypothesis mentioned above and are not entirely understood until today. Whereas the entire cohort of the Dutch trial showed a better LRR with SC-RT without differences in OS, an OS benefit of 50 or $40 \%$ was found only in the subgroup of patients with negative CRM when SC-RT was applied or not [5]. The authors of the British MRC CR07 trial presented similar results [6] and additionally demonstrated that even patients with optimal TME significantly benefit from SC-RT in terms of LRR (1 vs. 7\%) [35]. There are hints that a subgroup of patients does not require preoperative SC-RT or LC-CRT, but from today's perspective reliable criteria to identify these patients are lacking.

The opposite question to that of local de-escalation is whether all patients undergoing neoadjuvant RT actually need surgery. For patients after LC-CRT, pathological complete remission (pCR) rates of $8-20 \%$ are reported $[7,11,12,36,37]$. These very good re- 
Table 2. Key trials for systemic escalation in neoadjuvant RT of rectal cancer

\begin{tabular}{|c|c|c|c|c|c|c|c|c|}
\hline Reference & Treatment & $\mathrm{n}$ & TME & $\mathrm{FU}$ & OS & LRR & $\mathrm{pCR}, \%$ & Comment \\
\hline Aschele et al. [44] & LC-CRT (+ ox) + surg vs. & 747 & yes & n.a. & n.a. & n.a. & 16 & response analysis \\
\hline STAR-01 & LC-CRT + surg & & & n.a. & n.a. & n.a. & 16 & survival not published yet \\
\hline Gérard et al. [36] & LC-CRT (+ ox) + surg vs. & 598 & yes & 37 & 3 years: $87.6 \%$ & 3 years: $4.4 \%$ & 19.2 & \\
\hline ACCORD 12/0405 & LC-CRT + surg & & & & 3 years: $88.3 \%$ & 3 years: $6.1 \%$ & 13.9 & \\
\hline \multicolumn{9}{|l|}{ PRODIGE 2} \\
\hline Rödel et al. [41] & LC-CRT $(+$ ox $)+$ surg & 1,236 & yes & 50 & 3 years: $88.7 \%$ & 3 years: $2.9 \%$ & $17^{\mathrm{a}}$ & \\
\hline CAO/ARO/AIO-04 & LC-CRT + surg & & & & 3 years: $88.0 \%$ & 3 years: $4.6 \%$ & $13^{\mathrm{a}}$ & \\
\hline Dewdney et al. [45] & CHT + LC-CRT $(+$ ox + cet $)+$ surg & 90 & yes & 37 & 2 years: $91.3 \%^{\mathrm{a}}$ & 3 years: $2.2 \%$ & 11 & \\
\hline EXPERT-C & $\mathrm{CHT}+\mathrm{LC}-\mathrm{CRT}(+\mathrm{ox})+$ surg & & & 32 & 2 years: $81.8 \%^{\mathrm{a}}$ & 3 years: $4.5 \%$ & 9 & \\
\hline
\end{tabular}

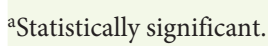

$\mathrm{n}=$ Patient number; TME = total mesorectal excision; $\mathrm{FU}=$ median follow-up; OS = overall survival; $\mathrm{LRR}=$ local relapse rate; $\mathrm{pCR}=$ pathological complete remission; ox = oxaliplatin; surg = surgery; cet = cetuximab; LC-CRT = long-course chemoradiotherapy (5-FU- or capecitabine-based); CHT = chemotherapy; n.a. $=$ not applicable.

sponders might be eligible for a non-surgical approach. The first experiences with a wait-and-see policy instead of surgery in a smaller number of patients with clinical complete remission (cCR) showed encouraging results $[38,39]$. Further, radiation and/or chemotherapeutic dose intensification beyond the usual LC-CRT regimen potentially increases the rate of CCR [40,41]. Though salvage strategies seem basically feasible, a rather high 1-year LRR of $15-35 \%[40,42]$ compared to the standard surgery-based approach is to be considered critically. Furthermore, the questions of optimal patient selection, adequate response assessment, and appropriate follow-up remain unanswered. So far, due to a lack of randomized evidence, organ-preserving treatment of rectal cancer is not recommended outside of clinical trials [43].

\section{Systemic Escalation}

The main debate in rectal cancer management predominantly dealt with local treatment strategies for a long time, but nowadays local control is excellent thanks to preoperative RT and TME. In contrast, overall survival rates are in need of improvement, and the major factor limiting the outcome is the appearance of metachronous distant metastases. The main approach to overcome this issue is the escalation of systemic therapy in the neoadjuvant setting, e.g. by addition of oxaliplatin to 5-FU- or capecitabine-based LC-RCT. Rödel et al. [41] demonstrated a significant improvement of the pCR rate (17 vs. $13 \%)$ and the 3-year disease-free survival rate (75.9 vs. $71.2 \%$ ) with versus without oxaliplatin, in the absence of substantial increases in side effects; however, there was no improvement in OS. The standard use of oxaliplatin remains controversial though, especially when considering non-beneficial results from other trials with increased toxicity rates [36, 44]. For the subgroup of KRAS-wildtype patients, Dewdney et al. [45] have shown a benefit in OS by adding cetuximab to neoadjuvant treatment in a small cohort, but the primary objective of the study, i.e. a superior pCR rate, was missed. A short overview of remarkable trials with systemic escalation is given in table 2.

Future approaches include further treatment escalation, e.g. with induction chemotherapy prior to LC-CRT as examined in the currently recruiting German CAO/ARO/AIO-12 trial, as well as the identification of favorable subgroups by means of molecular parameters potentially offering new treatment targets.

\section{Special Situations}

\section{Oligometastases}

About 20 years ago, the definition of oligometastatic disease as an intermediate cancer stage between locally limited tumor spread and disseminated metastases was proposed by Hellman and Weichselbaum [46] and has increasingly been established in clinical practice ever since. The relevance of this concept including local treatment of an assumed systemic disease was demonstrated by some comprehensive works investigating the role of surgery for CRC liver metastases and showing 5-year OS rates of 25-47\% [47-50]. Alternatively, less invasive locally ablative concepts such as radiofrequency ablation (RFA) or stereotactic body radiotherapy (SBRT) have emerged. Though large comparative trials are lacking, SBRT for liver metastases has shown beneficial results in CRC patients with 1-year local control rates of $56-100 \%$ [51]. Thus, SBRT is an excellent option for the local treatment of metastases with a good outcome and low toxicity rates, particularly for patients not suitable for surgery due to comorbidities or difficult technical resectability.

\section{Re-Irradiation}

In case of relapse, $\mathrm{R} 0$ resection is the most important prognostic marker. Hence, the use of surgery as radically as possible and 
maintainable is the standard of care for locally recurrent rectal cancer. When safe resection with negative resection margins is questionable, a combination with neoadjuvant CRT is recommended in all patients that have not been treated with SC-RT or LC-CRT in first-line therapy. Nevertheless, also in patients with previous pelvic $\mathrm{RT}$ retreatment is useful under certain limitations. Recent analyses have demonstrated that re-irradiation positively influences resectability, resulting in a favorable OS [52]. On average, 30-40 Gy are applied in repeated RT depending on initial doses and elapsed time from initial treatment [53]. However, there is a huge variety of applied re-irradiation concepts including normofractionated external beam RT [54], hyperfractionated regimens [55], and intraoperative RT [56-59]. In patients re-irradiated within curative concepts, median OS is 39-60 months [53]. In patients in palliative settings, median OS is $12-16$ months, and symptomatic relief, i.e. reduction of pain or tumor bleeding, can be achieved in the majority of cases $[53,54]$. Acute toxicity seems acceptable with 9-20\% (diarrhea), but the assessment of late side effects is difficult due to a lack of data so far [53]. Finally, particle RT with protons or heavy ions might allow further dose escalation in re-irradiation of rectal cancer without increasing toxicity, but clinical results in a larger number of patients are lacking $[60,61]$.

\section{Conclusion}

Radiotherapeutic concepts are crucial for the primary management of locally advanced rectal cancer and a helpful tool in the management of recurrent or oligometastatic CRC. Future research will have to focus on a better treatment selection for stage II/III patients in the primary setting and to find strategies to prevent prospective failure and improve long-term OS.

\section{Disclosure Statement}

The authors declare that they have no financial support or conflicts of interest pertaining to this report.

\section{References}

1 Torre LA, Bray F, Siegel RL, Ferlay J, Lortet-Tieulent J, Jemal A: Global cancer statistics, 2012. CA Cancer J Clin 2015;65:87-108.

2 Folkesson J, Birgisson H, Pahlman L, Cedermark B, Glimelius B, Gunnarsson U: Swedish Rectal Cancer Trial: long lasting benefits from radiotherapy on survival and local recurrence rate. J Clin Oncol 2005;23: 5644-5650.

3 Heald RJ, Husband EM, Ryall RD: The mesorectum in rectal cancer surgery - the clue to pelvic recurrence? $\mathrm{Br}$ J Surg 1982;69:613-616.

4 Heald RJ, Karanjia ND: Results of radical surgery for rectal cancer. World J Surg 1992;16:848-857.

5 van Gijn W, Marijnen CA, Nagtegaal ID, Kranenbarg EM, Putter H, Wiggers T, Rutten HJ, Pahlman L Glimelius B, van de Velde CJ; Dutch Colorectal Cancer Group: Preoperative radiotherapy combined with total mesorectal excision for resectable rectal cancer: 12-year follow-up of the multicentre, randomised controlled TME trial. Lancet Oncol 2011;12:575-582.

6 Sebag-Montefiore D, Stephens RJ, Steele R, Monson J, Grieve R, Khanna S, Quirke P, Couture J, de Metz C, Myint AS, Bessell E, Griffiths G, Thompson LC, Parmar M: Preoperative radiotherapy versus selective postoperative chemoradiotherapy in patients with rectal cancer (MRC CR07 and NCIC-CTG C016): a multicentre, randomised trial. Lancet 2009;373:811-820.

7 Sauer R, Becker H, Hohenberger W, Rodel C, Wittekind C, Fietkau R, Martus P, Tschmelitsch J, Hager E, Hess CF, Karstens JH, Liersch T, Schmidberger H, Raab R; German Rectal Cancer Study Group: Preoperative versus postoperative chemoradiotherapy for rectal cancer. N Engl J Med 2004;351:1731-1740.

-8 Sauer R, Liersch T, Merkel S, Fietkau R, Hohenberger W, Hess C, Becker H, Raab HR, Villanueva MT, Witzigmann H, Wittekind C, Beissbarth T, Rodel C: Preoperative versus postoperative chemoradiotherapy for locally advanced rectal cancer: results of the German CAO/ARO/AIO-94 randomized phase III trial after a median follow-up of 11 years. J Clin Oncol 2012;30: 1926-1933.
Gerard JP, Conroy T, Bonnetain F, Bouche O, Chapet O, Closon-Dejardin MT, Untereiner M, Leduc B, Francois E, Maurel J, Seitz JF, Buecher B, Mackiewicz R, Ducreux M, Bedenne L: Preoperative radiotherapy with or without concurrent fluorouracil and leucovorin in T3-4 rectal cancers: results of FFCD 9203. J Clin Oncol 2006;24:4620-4625.

10 Hofheinz RD, Wenz F, Post S, et al: Chemoradiotherapy with capecitabine versus fluorouracil for locally advanced rectal cancer: a randomised, multicentre, non-inferiority, phase 3 trial. Lancet Oncol 2012;13: 579-588.

11 Bujko K, Nowacki MP, Nasierowska-Guttmejer A, Michalski W, Bebenek M, Kryj M: Long-term results of a randomized trial comparing preoperative shortcourse radiotherapy with preoperative conventionally fractionated chemoradiation for rectal cancer. $\mathrm{Br} \mathrm{J}$ Surg 2006;93:1215-1223.

12 Ngan SY, Burmeister B, Fisher RJ, Solomon M, Goldstein D, Joseph D, Ackland SP, Schache D, McClure B, McLachlan SA, McKendrick J, Leong T, Hartopeanu C, Zalcberg J, Mackay J: Randomized trial of shortcourse radiotherapy versus long-course chemoradiation comparing rates of local recurrence in patients with T3 rectal cancer: Trans-Tasman Radiation Oncology Group trial 01.04. J Clin Oncol 2012;30:38273833.

13 De Caluwe L, Van Nieuwenhove Y, Ceelen WP: Preoperative chemoradiation versus radiation alone for stage II and III resectable rectal cancer. Cochrane Database Syst Rev 2013;2:CD006041.

14 McCarthy K, Pearson K, Fulton R, Hewitt J: Pre-operative chemoradiation for non-metastatic locally advanced rectal cancer. Cochrane Database Syst Rev 2012; 12:CD008368.

15 National Comprehensive Cancer Network (NCCN), NCCN Clinical Practical Guidelines in Oncology: Rectal Cancer; version 01.2016. www.nccn.org/professionals/ physician_gls/pdf/rectal.pdf (last accessed January 24, 2016).
6 Glimelius B, Tiret E, Cervantes A, Arnold D; ESMO Guidelines Working Group: Rectal cancer: ESMO Clinical Practice Guidelines for diagnosis, treatment and follow-up. Ann Oncol 2013;24(suppl 6):vi81-88.

17 Leitlinienprogramm Onkologie (Deutsche Krebsgesellschaft Deutsche Krebshilfe, AWMF), S3-Leitlinie Kolorektales Karzinom, Langversion 1.1, 2014, AWMF Registrierungsnummer: 021-007OL. www.leitlinienprogramm-onkologie.de/Leitlinien.7.0.html (last accessed January 24, 2016).

18 Peeters KC, van de Velde CJ, Leer JW, Martijn H, Junggeburt JM, Kranenbarg EK, Steup WH, Wiggers T, Rutten HJ, Marijnen CA: Late side effects of shortcourse preoperative radiotherapy combined with total mesorectal excision for rectal cancer: increased bowel dysfunction in irradiated patients - a Dutch colorectal cancer group study. J Clin Oncol 2005;23:6199-6206.

19 Pollack J, Holm T, Cedermark B, Altman D, Holmstrom B, Glimelius B, Mellgren A: Late adverse effects of short-course preoperative radiotherapy in rectal cancer. Br J Surg 2006;93:1519-1525.

20 Stephens RJ, Thompson LC, Quirke P, Steele R, Grieve R, Couture J, Griffiths GO, Sebag-Montefiore D: Impact of short-course preoperative radiotherapy for rectal cancer on patients' quality of life: data from the Medical Research Council CR07/National Cancer Institute of Canada Clinical Trials Group C016 randomized clinical trial. J Clin Oncol 2010;28:4233-4239.

21 Wolff HA, Conradi LC, Beissbarth T, Leha A, Hohenberger W, Merkel S, Fietkau R, Raab HR, Tschmelitsch J, Hess CF, Becker H, Wittekind C, Sauer R, Rodel C, Liersch T; German Rectal Cancer Study Group: Gender affects acute organ toxicity during radiochemotherapy for rectal cancer: long-term results of the German CAO/ARO/AIO-94 phase III trial. Radiother Oncol 2013;108:48-54.

22 Bruheim K, Tveit KM, Skovlund E, Balteskard L, Carlsen E, Fossa SD, Guren MG: Sexual function in females after radiotherapy for rectal cancer. Acta Oncol 2010;49:826-832. 
23 Nout RA, Smit VT, Putter H, Jurgenliemk-Schulz IM, Jobsen JJ, Lutgens LC, van der Steen-Banasik EM, Mens JW, Slot A, Kroese MC, van Bunningen BN, Ansink AC, van Putten WL, Creutzberg CL; PORTEC Study Group: Vaginal brachytherapy versus pelvic external beam radiotherapy for patients with endometrial cancer of high-intermediate risk (PORTEC-2): an open-label, non-inferiority, randomised trial. Lancet 2010;375:816-823.

24 Nout RA, van de Poll-Franse LV, Lybeert ML, Warlam-Rodenhuis CC, Jobsen JJ, Mens JW, Lutgens LC, Pras B, van Putten WL, Creutzberg CL: Long-term outcome and quality of life of patients with endometrial carcinoma treated with or without pelvic radiotherapy in the post operative radiation therapy in endometrial carcinoma 1 (PORTEC-1) trial. J Clin Oncol 2011;29:1692-1700.

25 Wiltink LM, Nout RA, Fiocco M, Meershoek-Klein Kranenbarg E, Jurgenliemk-Schulz IM, Jobsen JJ, Nagtegaal ID, Rutten HJ, van de Velde CJ, Creutzberg CL, Marijnen CA: No increased risk of second cancer after radiotherapy in patients treated for rectal or endometrial cancer in the randomized TME, PORTEC-1, and PORTEC-2 trials. J Clin Oncol 2015;33:1640-1646.

26 Kulu Y, Tarantino I, Billeter AT, Diener MK, Schmidt T, Buchler MW, Ulrich A: Comparative outcomes of neoadjuvant treatment prior to total mesorectal excision and total mesorectal excision alone in selected stage II/III low and mid rectal cancer. Ann Surg Oncol 2016;23:106-113.

27 Ulrich A, Weitz J, Slodczyk M, Koch M, Jaeger D, Munter M, Buchler MW: Neoadjuvant treatment does not influence perioperative outcome in rectal cancer surgery. Int J Radiat Oncol Biol Phys 2009;75:129-136.

-28 Droge LH, Weber HE, Guhlich M, Leu M, Conradi LC Gaedcke J, Hennies S, Herrmann MK, Rave-Frank M, Wolff HA: Reduced toxicity in the treatment of locally advanced rectal cancer: a comparison of volumetric modulated arc therapy and 3D conformal radiotherapy. BMC Cancer 2015;15:750.

-29 Samuelian JM, Callister MD, Ashman JB, YoungFadok TM, Borad MJ, Gunderson LL: Reduced acute bowel toxicity in patients treated with intensity-modulated radiotherapy for rectal cancer. Int J Radiat Oncol Biol Phys 2012;82:1981-1987.

30 Wolff HA, Wagner DM, Conradi LC, Hennies S, Ghadimi M, Hess CF, Christiansen H: Irradiation with protons for the individualized treatment of patients with locally advanced rectal cancer: a planning study with clinical implications. Radiother Oncol 2012;102: 30-37.

31 Lai LL, Fuller CD, Kachnic LA, Thomas CR Jr: Can pelvic radiotherapy be omitted in select patients with rectal cancer? Semin Oncol 2006;33(6 suppl 11):S7074.

\$2 Ulrich A, Weitz J, Buchler MW: Rectal cancer. How much radiotherapy do surgery patients need? (Article in German). Chirurg 2009;80:266-273.

33 Battersby NJ, How P, Moran B, Stelzner S, West NP, Branagan G, Strassburg J, Quirke P, Tekkis P, Pedersen BG, Gudgeon M, Heald B, Brown G, Group MIS: Prospective validation of a low rectal cancer magnetic resonance imaging staging system and development of a local recurrence risk stratification model: the MERCURY II study. Ann Surg 2015;263:751-760.

34 MERCURY Study Group: Extramural depth of tumor invasion at thin-section MR in patients with rectal cancer: results of the MERCURY study. Radiology 2007; 243:132-139.
35 Quirke P, Steele R, Monson J, Grieve R, Khanna S, Couture J, O'Callaghan C, Myint AS, Bessell E, Thompson LC, Parmar M, Stephens RJ, Sebag-Montefiore D; MRC CR07/NCIC-CTG CO16 Trial Investigators; NCRI Colorectal Cancer Study Group: Effect of the plane of surgery achieved on local recurrence in patients with operable rectal cancer: a prospective study using data from the MRC CR07 and NCIC-CTG CO16 randomised clinical trial. Lancet 2009;373:821828.

36 Gerard JP, Azria D, Gourgou-Bourgade S, et al: Clinical outcome of the ACCORD 12/0405 PRODIGE 2 randomized trial in rectal cancer. J Clin Oncol 2012;30: 4558-4565.

37 Rodel C, Liersch T, Becker H, et al; German Rectal Cancer Study Group: Preoperative chemoradiotherapy and postoperative chemotherapy with fluorouracil and oxaliplatin versus fluorouracil alone in locally advanced rectal cancer: initial results of the German $\mathrm{CAO} / \mathrm{ARO} / \mathrm{AIO}-04$ randomised phase 3 trial. Lancet Oncol 2012;13:679-687.

38 Habr-Gama A, Perez RO, Nadalin W, Sabbaga J, Ribeiro U Jr, Silva e Sousa AH J., Campos FG, Kiss DR, Gama-Rodrigues J: Operative versus nonoperative treatment for stage 0 distal rectal cancer following chemoradiation therapy: long-term results. Ann Surg 2004;240:711-717; discussion 717-718.

39 Maas M, Beets-Tan RG, Lambregts DM, Lammering G, Nelemans PJ, Engelen SM, van Dam RM, Jansen RL, Sosef M, Leijtens JW, Hulsewe KW, Buijsen J, Beets GL: Wait-and-see policy for clinical complete responders after chemoradiation for rectal cancer. J Clin Oncol 2011;29:4633-4640.

40 Appelt AL, Ploen J, Harling H, Jensen FS, Jensen LH, Jorgensen JC, Lindebjerg J, Rafaelsen SR, Jakobsen A: High-dose chemoradiotherapy and watchful waiting for distal rectal cancer: a prospective observational study. Lancet Oncol 2015;16:919-927.

41 Rodel C, Graeven U, Fietkau R, et al; German Rectal Cancer Study Group: Oxaliplatin added to fluorouracil-based preoperative chemoradiotherapy and postoperative chemotherapy of locally advanced rectal cancer (the German CAO/ARO/AIO-04 study): final results of the multicentre, open-label, randomised, phase 3 trial. Lancet Oncol 2015;16:979-989.

42 Habr-Gama A, Gama-Rodrigues J, Sao Juliao GP, Proscurshim I, Sabbagh C, Lynn PB, Perez RO: Local recurrence after complete clinical response and watch and wait in rectal cancer after neoadjuvant chemoradiation: impact of salvage therapy on local disease control. Int J Radiat Oncol Biol Phys 2014;88:822-828.

43 Marijnen CA: Organ preservation in rectal cancer: have all questions been answered? Lancet Oncol 2015; 16:e13-22.

44 Aschele C, Cionini L, Lonardi S, Pinto C, Cordio S, Rosati G, Artale S, Tagliagambe A, Ambrosini G, Rosetti P, Bonetti A, Negru ME, Tronconi MC, Luppi G, Silvano G, Corsi DC, Bochicchio AM, Chiaulon G, Gallo $\mathrm{M}$, Boni L: Primary tumor response to preoperative chemoradiation with or without oxaliplatin in locally advanced rectal cancer: pathologic results of the STAR-01 randomized phase III trial. J Clin Oncol 2011;29:2773-2780.

45 Dewdney A, Cunningham D, Tabernero J, Capdevila J, Glimelius B, Cervantes A, Tait D, Brown G, Wotherspoon A, Gonzalez de Castro D, Chua YJ, Wong R, Barbachano Y, Oates J, Chau I: Multicenter randomized phase II clinical trial comparing neoadjuvant oxaliplatin, capecitabine, and preoperative radiotherapy with or without cetuximab followed by total mesorectal excision in patients with high-risk rectal cancer (EXPERT-C). J Clin Oncol 2012;30:1620-1627.

46 Hellman S, Weichselbaum RR: Oligometastases. J Clin Oncol 1995;13:8-10.
47 House MG, Ito H, Gonen M, Fong Y, Allen PJ, DeMatteo RP, Brennan MF, Blumgart LH, Jarnagin WR, D’Angelica MI: Survival after hepatic resection for metastatic colorectal cancer: trends in outcomes for 1,600 patients during two decades at a single institution. J Am Coll Surg 2010;210:744-752, 752-754.

48 Nordlinger B, Guiguet M, Vaillant JC, Balladur P, Boudjema K, Bachellier P, Jaeck D: Surgical resection of colorectal carcinoma metastases to the liver. A prognostic scoring system to improve case selection, based on 1568 patients. Association Francaise de Chirurgie. Cancer 1996;77:1254-1262.

49 Robertson DJ, Stukel TA, Gottlieb DJ, Sutherland JM, Fisher ES: Survival after hepatic resection of colorectal cancer metastases: a national experience. Cancer 2009; 115:752-759.

50 Wei AC, Greig PD, Grant D, Taylor B, Langer B, Gallinger S: Survival after hepatic resection for colorectal metastases: a 10-year experience. Ann Surg Oncol 2006; 13:668-676.

51 Sterzing F, Brunner TB, Ernst I, Baus WW, Greve B, Herfarth K, Guckenberger M: Stereotactic body radiotherapy for liver tumors: principles and practical guidelines of the DEGRO Working Group on Stereotactic Radiotherapy. Strahlenther Onkol 2014;190: 872-881.

52 van der Meij W, Rombouts AJ, Rutten H, Bremers AJ, de Wilt JH: Treatment of locally recurrent rectal carcinoma in previously (chemo)irradiated patients: a review. Dis Colon Rectum 2016;59:148-156.

53 Guren MG, Undseth C, Rekstad BL, Braendengen M, Dueland S, Spindler KL, Glynne-Jones R, Tveit KM: Reirradiation of locally recurrent rectal cancer: a systematic review. Radiother Oncol 2014;113:151-157.

54 Mohiuddin M, Marks G, Marks J: Long-term results of reirradiation for patients with recurrent rectal carcinoma. Cancer 2002;95:1144-1150.

55 Valentini V, Morganti AG, Gambacorta MA, Mohiuddin M, Doglietto GB, Coco C, De Paoli A, Rossi C, Di Russo A, Valvo F, Bolzicco G, Dalla Palma M; Study Group for Therapies of Rectal Malignancies (STORM): Preoperative hyperfractionated chemoradiation for locally recurrent rectal cancer in patients previously irradiated to the pelvis: a multicentric phase II study. Int J Radiat Oncol Biol Phys 2006;64:1129-1139.

56 Haddock MG, Gunderson LL, Nelson H, Cha SS, Devine RM, Dozois RR, Wolff BG: Intraoperative irradiation for locally recurrent colorectal cancer in previously irradiated patients. Int J Radiat Oncol Biol Phys 2001;49:1267-1274.

57 Haddock MG, Miller RC, Nelson H, Pemberton JH, Dozois EJ, Alberts SR, Gunderson LL: Combined modality therapy including intraoperative electron irradiation for locally recurrent colorectal cancer. Int J Radiat Oncol Biol Phys 2011;79:143-150.

58 Roeder F, Goetz JM, Habl G, Bischof M, Krempien R, Buechler MW, Hensley FW, Huber PE, Weitz J, Debus $\mathrm{J}$ : Intraoperative electron radiation therapy (IOERT) in the management of locally recurrent rectal cancer. BMC Cancer 2012;12:592.

59 Rutten HJ, Mannaerts GH, Martijn H, Wiggers T: Intraoperative radiotherapy for locally recurrent rectal cancer in The Netherlands. Eur J Surg Oncol 2000; (26 suppl A):S16-20.

60 Combs SE, Kieser M, Habermehl D, Weitz J, Jager D, Fossati P, Orrechia R, Engenhart-Cabillic R, Potter R, Dosanjh M, Jakel O, Buchler MW, Debus J: Phase I/II trial evaluating carbon ion radiotherapy for the treatment of recurrent rectal cancer: the PANDORA-01 trial. BMC Cancer 2012;12:137.

61 Habermehl D, Wagner M, Ellerbrock M, Buchler MW, Jakel O, Debus J, Combs SE: Reirradiation using carbon ions in patients with locally recurrent rectal cancer at HIT: first results. Ann Surg Oncol 2015;22:2068-2074. 